\title{
Divided attention performance and the matching law
}

\author{
TIMOTHY A. SHAHAN and CHRISTOPHER A. PODLESNIK \\ Utah State University, Logan, Utah
}

\begin{abstract}
This experiment examined the applicability of the generalized matching law to changes in dividedattention performance produced by variations in relative reinforcement rate. Pigeons were exposed to a delayed matching-to-sample procedure in which compound samples (color + line orientation) and element comparisons (two colors or two line orientations) were used. The relative rate of reinforcement for accurate matches on the two types of comparison trials was varied. Variations in relative accuracy with changes in relative reinforcement were well described by the generalized matching law. We suggest that the bias and sensitivity parameters of the generalized matching law may measure the contributions of sensory activation and stimulus pertinence, respectively, to divided-attention performance. Additional work using similar analyses might contribute to a more general quantitative account of how differential consequences contribute to decision processes involved in the allocation of attention.
\end{abstract}

Attention is typically characterized as being of limited capacity and selective with respect to the information that is processed (see Pashler, 1998, and Styles, 1997, for reviews). Although many features of information to be processed affect how attention is allocated, Norman (1968) noted the important role played by the pertinence of stimuli. The pertinence of a particular stimulus reflects the importance of the stimulus to the organism and can be considered to be related to the goals of the organism and its history with that stimulus. Endogenous or top-down goal-directed factors in attentional control are widely recognized in cognitive psychology (see, e.g., Posner, 1980; see also Yantis, 2000, for a review) and are generally attributed to the actions of an as yet poorly specified central executive (see Norman \& Shallice, 1986; see also Styles, 1997, for a review and criticism). Although attentional control in the human laboratory is almost ubiquitously accomplished through instructions, such attentional control in the natural environment likely varies as a function of differential consequences encountered as a result of patterns of attending to particular environmental features (see Lacourse \& Blough, 1998; McIlvane, Dube, \& Callahan, 1996). Consistent with a role for experiential influences on the control of attention, Gopher (1992) found that the control of attention appears to be in part a learned skill, modifiable by training. Given these considerations, it may be useful to examine the utility of applying quan-

This research was funded by National Institute of Mental Health Gran MH072621 (T.A.S). The authors thank Amy Odum, Stacey McFeron, and most especially Tony Nevin for their comments and suggestions, and Ericka Bailey, Katie Burke, Corina Jimenez-Gomez, and Ryan Ward for their help in conducting this research. Address correspondence to T. A. Shahan, Department of Psychology, Utah State University, Logan, UT, 84322 (e-mail: tim.shahan@usu.edu). titative behavioral choice theories (i.e., the matching law) to attending.

The matching law states that when organisms are confronted with a choice situation, they allocate their behavior to two options in proportion to the distribution of reinforcers obtained from the two options (Herrnstein, 1961). To account for common deviations from the strict matching law, Baum $(1974,1979)$ proposed the generalized matching law, which states that the ratio of behavior at two options is a power function of the ratio of reinforcers obtained at the options. In logarithmic form, this relation is

$$
\log \left(\frac{B_{1}}{B_{2}}\right)=a \log \left(\frac{R_{1}}{R_{2}}\right)+\log b,
$$

where $B_{1}$ and $B_{2}$ refer to Behaviors 1 and 2, respectively, and $R_{1}$ and $R_{2}$ refer to reinforcers for $B_{1}$ and $B_{2}$. The parameters $a$ and $\log b$ represent sensitivity of behavior ratios to reinforcement ratios, and bias for one response over the other, respectively. The matching law has been shown to be widely applicable across species and procedures (see Davison \& McCarthy, 1988, for a review), including human macrosaccadic eye movements in a signal detection task (Schroeder \& Holland, 1969). Versions of the generalized matching law have been extended to account for conditional discrimination performance (see Davison \& Nevin, 1999; Nevin, Davison, \& Shahan, 2005, for reviews). These models describe discriminative performance as being the result of both the discriminability of the stimuli and differential rates of reinforcement for reporting that a given stimulus has or has not occurred. Nevin et al.'s model further posits that conditional discrimination performance depends on the probability of attending to sample and comparison stimuli, and that attending to both sample stimuli and comparison stimuli is governed by the rate of reinforcement associated with that 
attending. Although these models have been quite successful at accounting for a range of phenomena in discriminative performance, they are not directed at describing how attention is allocated in situations where more than one dimension is relevant for solving a discrimination (i.e., divided attention is required).

Classic two-stage models of discrimination learning also suggest a role for differential reinforcement in the control of attention. These models suggest that subjects learn (1) to attend to the relevant stimuli or stimulus dimension and (2) which stimulus value is associated with reinforcement (e.g., Lovejoy, 1965; Mackintosh, 1975; Sutherland \& Mackintosh, 1971; Zeaman \& House, 1963). The relevance of a dimension is established by arranging differential relations between presentations of stimuli along that dimension and the delivery of reinforcement (see, e.g., Blough, 1969; Leith \& Maki, 1975; Mackintosh \& Little, 1969). Mackintosh's (1975) attention theory suggests that attention to a stimulus increases when that stimulus is a better predictor of reward than other available stimuli are and that attention to a stimulus decreases when other stimuli predict reward as well as or better than that stimulus. Similarly, Lubow's (1989) conditioned attention theory suggests that attention is a response that either increases or decreases, depending on whether it is followed by reward or not. Although our approach is related to those of Mackintosh and Lubow in assuming a role for reinforcement in the deployment of attention, our goal is to study the relation between divided attention and behavioral choice theory, rather than to explain basic conditioning phenomena.

In terms of studying divided attention directly, Riley and colleagues have suggested that it is most appropriate to use procedures that require a division of attention under conditions of limited processing (Riley \& Leith, 1976; Riley \& Roitblat, 1978; Zentall \& Riley, 2000; cf. Mackintosh, 1975). A procedure that has been useful in the study of divided attention in pigeons was developed by Maki and Leuin (1972). In this delayed matching-tosample (DMTS) procedure, pigeons are sometimes presented with compound samples that comprise a combination of two elements and sometimes are presented with samples that consist of just one of the elements. In their experiment, the two types of elements were line orientation (i.e., vertical or horizontal) and key color (i.e., red or blue). Following both types of sample presentations, two comparison stimuli were presented and responses to the comparison that appeared in the sample were reinforced with food presentations. Comparison stimuli were always the two line stimuli or the two color stimuli. Maki and Leuin found that the sample duration maintaining accuracy at $80 \%$ correct was longer for compound sample trials than for element sample trials. Similarly, Maki and Leith (1973) found that when sample duration was fixed at the same duration for compound and element sample trials, accuracy was consistently higher following element samples (cf. Gottselig, Wasserman, \& Young, 2001; Langley \& Riley, 1993; Leith \& Maki, 1975; Santi, Grossi, \& Gibson, 1982; Zentall, Sherburne, \& Zhang, 1997). Although other hypotheses have been proposed (e.g., generalization decrement, coding decrement, comparison uncertainty, retrieval deficit), the bulk of the data support the suggestion that this "element superiority effect" results from the detrimental effects of a division of attention between the elements with compound samples (see Zentall, 2005, and Zentall \& Riley, 2000, for reviews).

When compound samples are presented in the divided attention task, the situation shares important characteristics with the concurrent schedules of reinforcement from which the matching law was derived. The distribution of attending to the two elements can be considered analogous to the distribution of responding to concurrently available schedules of reinforcement. Thus, the allocation of attending to each of the elements in a compound sample may vary with the relative rate of reinforcement obtained by attending to those elements in a manner consistent with the matching law. In studies of divided attention, however, relative rate of reinforcement for attending to the different elements has always been either .5 when element comparisons from both dimensions are presented or 1.0 when one dimension is made irrelevant by never presenting comparisons from that dimension (Leith \& Maki, 1975).

In the present experiment, the effects of variations in relative reinforcement rate on divided attention performance were examined using a DMTS procedure with compound samples (color + line orientation) and element comparisons (two colors or two line orientations presented with $p=.5$ ). A generalized matching law analysis was conducted on relative accuracy data as a function of variations in relative reinforcement for correct matches on the two types of element comparison trials.

\section{METHOD}

\section{Subjects}

The subjects were 4 homing pigeons maintained at approximately $80 \%$ of their free-feeding weights $( \pm 15 \mathrm{~g})$ by postsession supplemental feeding as was necessary. The pigeons varied in age and had extensive experience with procedures similar to those arranged in the present experiment. When not in the experimental sessions, the pigeons were housed in individual cages in a temperature-controlled colony with a 12:12-h light:dark cycle (lights on at 7:00 a.m.) and had free access to water.

\section{Apparatus}

The experiment was conducted in four Lehigh Valley Electronics pigeon chambers measuring $350 \mathrm{~mm}$ long, $350 \mathrm{~mm}$ high, and $300 \mathrm{~mm}$ wide. Three response keys were centered on the front panel, $83 \mathrm{~mm}$ apart (center to center); the panel was $240 \mathrm{~mm}$ above the floor. The keys measured $25 \mathrm{~mm}$ in diameter, and it took about $0.1 \mathrm{~N}$ of force to operate them. A projector could transilluminate each key with white, blue, green, a white horizontal line on a black background, or a white vertical line on a black background. Compound stimuli composed of a color with a superimposed white line could be produced by simultaneously lighting a color and line stimulus. Reinforcers consisted of 1.8 -sec presentations of pigeon checkers from a hopper. The hopper was accessible, when raised, through a 50 - $\mathrm{mm}$ wide $\times 55$ - $\mathrm{mm}$ tall aperture located on the midline of the work panel with its center $100 \mathrm{~mm}$ from the floor. A 28-V DC clear bulb illuminated the aperture, and all other lights were extinguished when the hopper was operated. General illumination was provided by a shielded $28-\mathrm{V}$ DC clear bulb mounted $45 \mathrm{~mm}$ above the center 
key. A ventilation fan and white noise masked extraneous sounds. Control of experimental events and data recording were conducted with Med Associates programming and interfacing.

\section{Procedure}

Training. All DMTS trials throughout the experiment were preceded by the presentation of a white trial-ready stimulus on the center key. Sample stimuli were presented following a single peck to the white center key. Training began with single-element DMTS trials, in which the sample consisted of either a single color (i.e., blue or green) or a single line orientation (i.e., horizontal or vertical) chosen at random. In the first session, a single response to the sample removed the sample and produced the comparison stimuli on the side keys. Comparison stimuli consisted of the two colors given a color sample and the two lines given a line sample. The location of the two comparison stimuli was determined randomly. A single peck to the comparison stimulus that matched the sample resulted in access to the hopper. Pecks to the comparison that did not match the sample turned off all stimuli for $2 \mathrm{sec}$ (hereafter, blackout). Across the next few daily sessions, the sample response requirement was increased to a fixed-ratio (FR) 10. A correction procedure was in effect in which the blackout was extended for $10 \mathrm{sec}$ followed by a re-presentation of the trial with the same sample stimulus and comparisons. This series of events recurred until the correct comparison was chosen and reinforcement was delivered. Following all hopper presentations, a 10 -sec intertrial interval (ITI) occurred, during which only the houselight was illuminated prior to the presentation of the next trial-ready stimulus. All training sessions consisted of 48 trials, not including any trials repeated because of incorrect comparison choices. Once performance was above $80 \%$ correct for approximately five sessions with both color and line samples for each individual pigeon, the single-element samples were replaced with compound samples.

Procedural details for training with compound sample stimuli were the same as for training with single-element samples, except that compound samples included one color and one line orientation simultaneously presented on the center key. Each of the four possible combinations of colors and line orientations was presented the same number of times (12 times each). Following completion of the FR 10 on the sample, the sample was removed and the two colors (hereafter, color trials) or two lines (hereafter, line trials) were immediately presented as comparison stimuli on the side keys. Color or line trials were presented with $p=.5$. Thus, sample stimuli always included a color and a line; however, it was unpredictable whether the two colors or two line orientations would be presented as comparison stimuli. A correct response consisted of a peck to the side key with the color or line orientation that matched the color or line from the sample. The final procedure was introduced for each pigeon when performance on both color and line trials was reliably above $80 \%$ correct for that pigeon.

Variation in relative reinforcement rate. The final procedure was similar to that for the training conditions, except that (1) the compound sample stimuli were terminated response independently $5 \mathrm{sec}$ after the peck to the trial-ready stimulus, (2) the number of trials per session was increased to 80 by presenting each color line compound sample 20 times, (3) reinforcement was presented with $p=.5$ for correct choices on both types of trials, and (4) there was no correction procedure. Following trials in which nonreinforced correct responses and incorrect responses occurred, the 2-sec blackout occurred followed by the 10 -sec ITI.

Following the initial exposure to the $1: 1(p=.5, p=.5)$ ratio of reinforcement, the probability of reinforcement for correct choices on color and line trials varied across conditions. Reinforcement probabilities for correct matches on color and line trials were varied to arrange ratios of reinforcement delivery of 1:9 $(p=.1, p=.9)$, $1: 3(p=.25, p=.75), 1: 1(p=.5, p=.5), 3: 1(p=.75, p=.25)$, and 9:1 $(p=.9, p=.1)$ across conditions. Conditions remained in effect for at least 16 sessions and until there were no systematic increasing or decreasing trends in percent correct across sessions for both color and line trials for each individual pigeon. Table 1 shows the order of conditions and number of sessions in each condition for each pigeon.

Accuracy on the two types of trials was used in the generalized matching law analysis. Accuracy was measured using $\log d$ (Davison \& Tustin, 1978), a measure of discrimination used extensively in applications of the matching law to conditional discrimination performance (see Davison \& Nevin, 1999). This measure is independent of bias, and, like response rates, it theoretically ranges from 0 (i.e., chance performance) to infinity (i.e., perfect performance). These metric properties make it appropriate for use in generalized matching law analyses. $\log d$ is calculated as follows:

$$
\log d=0.5 \log \left[\left(\frac{\operatorname{Corr}_{S 1}}{\operatorname{Incorr}_{S 1}}\right)\left(\frac{\operatorname{Corr}_{S 2}}{\operatorname{Incorr}_{S 2}}\right)\right],
$$

where Corr ${ }_{S 1}$ and Incorr $_{S 1}$ refer to correct and incorrect matches following Sample 1 (e.g., blue), and Corr $_{S 2}$ and Incorr $_{S 2}$ refer to correct and incorrect matches following Sample 2 (e.g., green). Log $d$ was calculated individually for color and line trials totaled across the last 16 sessions of each condition. Although $\log d$ is undefined when either Incorr $_{S 1}$ or Incorr $_{S 2}$ equals zero, there was always at least one error for both stimuli in color and line trials in the final 16 sessions of each condition.

To apply the generalized matching law to the data, Equation 1 was modified to account for relative accuracies. In this modification, accuracies as measured by $\log d$ replace the simple behavior counts used in Equation 1. Given that (1) on the basis of the rules of logarithms, $\log \left(B_{1} / B_{2}\right)=\log \left(B_{1}\right)-\log \left(B_{2}\right)$, and (2) $\log d$ is already expressed in logarithmic terms, the difference between $\log d$ values on color and line trials (i.e., $\log d_{\mathrm{C}}-\log d_{\mathrm{L}}$ ) is used as the measure of relative accuracy to be consistent with the use of log behavior ratios [i.e., $\left.\log \left(B_{1} / B_{2}\right)\right]$ in Equation 1. In addition, the reinforcers obtained for accurate matches on color (i.e., $R_{\mathrm{C}}$ ) and line (i.e., $R_{\mathrm{L}}$ ) trials are substituted for the reinforcers obtained for two concurrent responses (i.e., $R_{1}$ and $R_{2}$ ) in Equation 1. With these modifications,

Iable 1

Order of Conditions and Number of Sessions in Each Condition for Each Pigeon

\begin{tabular}{ccc}
\hline Pigeon & Condition & Sessions \\
\hline 233 & $1: 1$ & 47 \\
& $3: 1$ & 39 \\
$9: 1$ & 61 \\
& $1: 1$ & 28 \\
& $1: 9$ & 37 \\
& $1: 3$ & 42 \\
& $1: 1$ & 44 \\
& $1: 3$ & 44 \\
& $1: 9$ & 54 \\
& $1: 1$ & 44 \\
& $3: 1$ & 27 \\
& $9: 1$ & 16 \\
& $1: 1$ & 37 \\
& $3: 1$ & 43 \\
& $9: 1$ & 29 \\
& $1: 1$ & 19 \\
& $1: 9$ & 26 \\
222 & $1: 3$ & 28 \\
& $1: 1$ & 38 \\
& $1: 3$ & 31 \\
& $1: 9$ & 28 \\
& $1: 1$ & 20 \\
& $3: 1$ & 50 \\
& $9: 1$ & 35 \\
\hline
\end{tabular}


the generalized matching law as applied to accuracies in the present experiment becomes

$$
\log d_{\mathrm{C}}-\log d_{\mathrm{L}}=a \log \left(\frac{R_{\mathrm{C}}}{\mathrm{R}_{\mathrm{L}}}\right)+\log b,
$$

where $\log d_{\mathrm{C}}$ and $\log d_{\mathrm{L}}$ refer to $\log d$ values for color and line trials, respectively. The parameter $a$ now represents sensitivity of relative accuracy to variations in the ratio of reinforcers obtained on color (i.e., $R_{\mathrm{C}}$ ) and line trials (i.e., $R_{\mathrm{L}}$ ). The parameter $\log b$ represents a bias in accuracy produced by proportionally higher accuracy on one type of trial than on the other, independent of variations in the reinforcement ratio. It is important to note that the value of $a$ is somewhat constrained by the requirement of at least one error for $S 1$ and $S 2$ in Equation 2 for both colors and lines. Even with this constraint, simulations reveal that in the present preparation, the value of $a$ in Equation 3 can exceed 2.0, a value far greater than that typically obtained with simple concurrent schedules of reinforcement.

\section{RESULTS}

Figure 1 shows the effects of variations in the probability of reinforcement on mean accuracy as measured with the more familiar proportion correct (top panel) and $\log d$ (bottom panel). Accuracy is plotted as a function of the probability of reinforcement on color trials. Thus, the
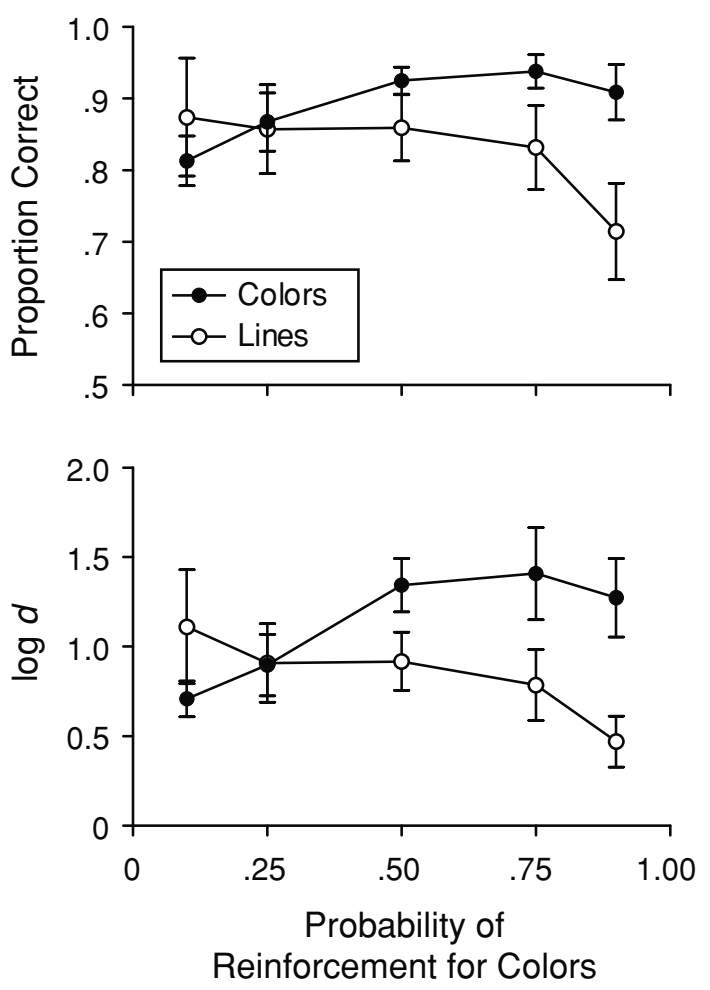

Figure 1. The top panel shows accuracy on color and line comparison trials measured as proportion correct and presented as a function of the probability of reinforcement for accurate matches on color trials. The probability of reinforcement on line trials is the complement of that on color trials. The bottom panel shows a similar analysis with accuracy measured by $\log d$ (see Equation 2). Data in both panels are means for the 4 pigeons and error bars represent $\pm 1 S E M$. probability of reinforcement on line trials is the complement of the abscissa value. There were significant interactions between trial type (i.e., line or color) and probability of reinforcement on color trials for both proportion correct $[F(4,12)=19.4, p<.001]$ and $\log d[F(4,12)=$ $11.9, p<.001]$. These interactions reflect the fact that accuracy on color trials increased but accuracy on line trials decreased as a function of increases in the probability of reinforcement on color trials. The increases or decreases in proportion correct as a function of the probability of reinforcement for color trials were confirmed by significant linear trends for increases in proportion correct on color trials $[F(1,3)=14.23, p<.033]$ and decreases on line trials $[F(1,3)=223.94, p<.001]$. There were similar significant linear trends in increases in $\log d$ on color trials $[F(1,3)=12.44, p<.038]$ and decreases on line trials $[F(1,3)=17.05, p<.026]$. Not surprisingly, given the nature of the interaction, there were no significant effects of type of trial for either measure of accuracy. There was a significant main effect of probability of reinforcement on proportion correct $[F(4,12)=4.6, p<.018]$, but not on $\log d$. This main effect is difficult to interpret, given the difference in outcome obtained with the two measures of accuracy. Given the superior metric properties of $\log d$ and the significant interaction obtained with both measures, we are inclined to view the main effect with proportion correct as relatively unimportant.

The top panel of Figure 2 shows a generalized matching law analysis of changes in relative accuracy as a function of relative reinforcement for accurate matches on the two types of trials. The figure shows the difference between $\log d$ values on line and color trials as a function of mean obtained log reinforcement ratios for accurate matches on the two types of trials. The fitted function represents the predictions of the generalized matching law (i.e., Equation 3 ). Equation 3 provided a good description of the data, accounting for $96 \%$ of the variance. The slope of the function (i.e., $a$ ), and thus sensitivity to variations in reinforcement ratio, was 0.57 . This value is significantly greater than zero $[t(3)=7.65, p<.001]$. Thus, relative accuracy on color and line trials was sensitive to variations in relative reinforcement rate. The intercept of the function (i.e., $\log b$ ) was 0.26 , a value that is significantly greater than zero $[t(3)=4.58, p<.02]$. The finding that the bias parameter was greater than zero reflects proportionally higher accuracies on color trials than on line trials across the range of reinforcement ratios. Similarly higher accuracies on color than on line trials have been obtained in previous research using related procedures (Langley \& Riley, 1993; Santi et al., 1982; Zentall et al., 1997).

The bottom panels of Figure 2 show fits of Equation 3 to data of individual pigeons. Across pigeons, $a$ values ranged from a low of 0.20 for Pigeon 233 to a high of 0.86 for Pigeon 1158. The bias parameter was greater than zero in 3 of 4 cases, with Pigeon 233 showing the strongest bias toward greater accuracy on color trials. Equation 3 accounted for greater than $85 \%$ of the variance for 3 of 4 pigeons, with the fit being considerably poorer for $\mathrm{Pi}$ geon 233. The poor fit and lower $a$ value for Pigeon 233 

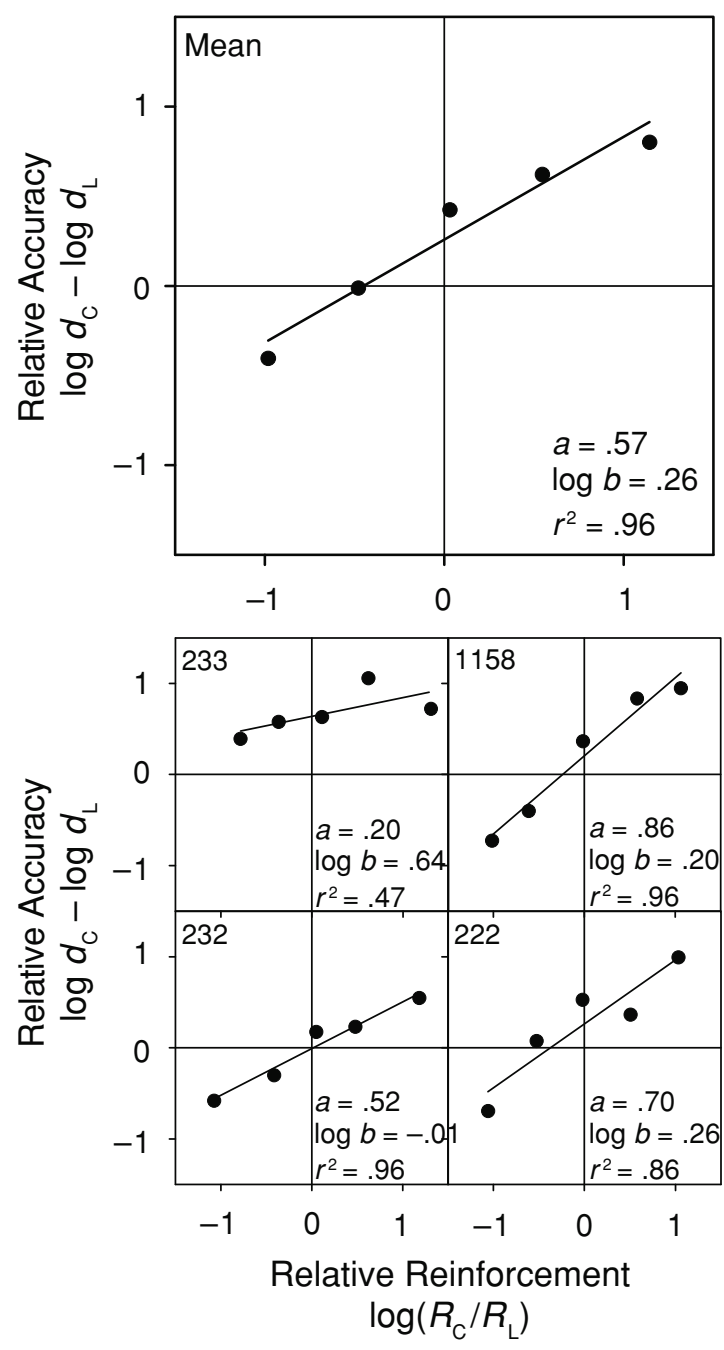

Figure 2. A generalized matching law analysis of relative accuracy on color and line trials (i.e., $\log d_{C}-\log d_{L}$ ) as a function of relative reinforcement obtained for accurate matches on color and line trials [i.e., $\log \left(R_{\mathrm{C}} / R_{\mathrm{L}}\right)$ ]. The top panel shows data averaged across pigeons. The bottom panels show data for individual pigeons. Fitted lines represent least squares regressions of Equation 3. Parameter values derived from the fits are presented in each panel.

may be related to the strong bias toward colors exhibited by this pigeon.

\section{DISCUSSION}

Accuracy on the two types of single-element comparison trials varied with the relative distribution of reinforcement for accurate matches on those two types of trials. The generalized matching law provided a good description of changes in relative accuracy with changes in the relative reinforcement distribution. Given that the relative distribution of reinforcement affected performance in this procedure, one question that arises is the source of the effect. This issue and its implications will be addressed in what follows.
One interpretation of the present results is that changes in accuracy on the two trial types reflect changes in processing of the elements of the sample stimuli. For example, when the payoff for lines was relatively high, the pigeons may have disproportionately allocated their attention during the sample to the lines. Roberts (1998) has suggested that when compound samples are presented, pigeons may not be able to attend to both dimensions at once and may switch back and forth between the two. This putative switching of attention between the two dimensions may be similar to the switching that occurs with simple operant behavior in concurrent schedules of reinforcement. Thus, the ability of the generalized matching law to describe the effects of relative reinforcement distribution on relative accuracy may reflect a fairly straightforward extension of the matching law to the allocation of attending to the elements constituting compound samples.

A potential difficulty for the interpretation above is that the mean sensitivity value (i.e., $a$ in Equation 3 ) obtained in the present experiment (i.e., 0.57) is somewhat lower than is typically obtained with concurrent schedules of reinforcement (i.e., approximately 0.8; Baum, 1979). However, it is important to note that the best approximations to matching in current schedules are obtained when a changeover delay is in effect (e.g., Herrnstein, 1961; Temple, Scown, \& Foster, 1995). A changeover delay reduces the rate of switching between the alternatives by imposing a penalty for switching from one alternative to the other. In the only experiment to examine a full range of relative reinforcement rates in the absence of a changeover delay, Temple et al. obtained a mean sensitivity value of 0.6 with chickens as subjects. However, Davison and McCarthy (1988) provided a point estimate of $a$ of approximately 0.2 from one relative reinforcement rate examined in an experiment by Shull and Pliskoff (1967) with rats and no changeover delay. Given that the pigeons in the present experiment were free to shift their attention from one dimension of the sample to the other without penalty, the obtained mean sensitivity value of 0.57 is within the range that might be expected. In addition, sensitivity may have been reduced by the fact that, unlike simple responding on current schedules, attending to a particular element of the sample did not lead directly to primary reinforcement. Rather, attending during the sample was followed by the presentation of the comparison stimuli and later by probabilistic primary reinforcement. Thus, despite the lower sensitivity value, it remains plausible that the allocation of attention to the elements of the compound samples was governed by the matching law. However, the present experiment does not exclude other possibilities.

For example, another interpretation of the present results is that changes in accuracy produced by variations in the relative distribution of reinforcement are the result of some other process having its effects at the comparison choice point. For example, some effects in the Pavlovian conditioning literature (e.g., blocking, the relative validity effect, overshadowing) once interpreted to reflect differential processing or associability of stimuli have been found to be due to failures of expression at the time of 
testing (see Wasserman \& Miller, 1997, for a review). Lamb (1991) suggested that the divided attention effects obtained with pigeons and compound samples may similarly be the result of retrieval failures, rather than capacity limitations at the time of initial processing. Zentall et al. (1997), however, provided empirical data inconsistent with the notion that divided attention effects with pigeons reflect a retrieval failure at the choice point. Nonetheless, it is possible that the differential reinforcement in the present experiment could have its effects by affecting performance at the choice point. For example, the changes in accuracy with variations in reinforcement for correct choices could reflect a motivational effect at the choice point. Thus, the pigeons could equally process both elements of the compounds, but if the lower reinforcement rate element is tested at the choice point, they may be less motivated to attend to the comparisons and/or choose the correct one.

The preceding considerations of the locus of the effects of differential reinforcement on divided attention performance in some ways parallel debate about early selection (closer to encoding) versus late selection (closer to response) models of attention (see Pashler, 1998, and Styles, 1997, for reviews). There is empirical evidence for both forms of selection, but early selection appears most likely under conditions of higher perceptual load (see Luck \& Vecera, 2002, for a review). The bulk of the evidence comparing DMTS accuracy with compound versus element samples with pigeons suggests that the compound samples used in the present experiment do tax pigeons' information processing capacity (see Zentall, 2005, and Zentall \& Riley, 2000, for reviews). Thus, in our view it seems reasonable to suggest that differential reinforcement in the present experiment may have an impact on initial processing of the compound samples.

One way of further assessing whether processing of the compound samples changes with variations in relative reinforcement rate would be to see whether such manipulations produce an attentional set in an intradimensional/ extradimensional (ID/ED) shift paradigm. In this paradigm, subjects are presented with a discrimination problem with stimuli composed of elements from two dimensions (e.g., color and shape). One dimension is relevant for solving the discrimination, and the other is irrelevant. Next, a similar discrimination problem is presented with novel stimuli from the same two dimensions. In an ID shift, the relevant dimension from the first problem remains relevant in the second problem. In an ED shift, the relevant dimension from the first problem becomes irrelevant in the second problem, and the previously irrelevant dimension becomes relevant. In a wide variety of species, ID shifts are learned more rapidly (i.e., fewer errors to criterion) than ED shifts, and this effect is generally attributed to the preservation of an attentional set acquired during the initial discrimination problem (see Dias, Robbins, \& Roberts, 1996, and Mackintosh, 1974, for reviews). A similar procedure could be used to assess whether differential reinforcement produces changes in attentional processing of the elements in the present procedure. In this test, an
ID shift would occur when the dimension corresponding to the previously more frequently reinforced element was relevant for a subsequent discrimination and the dimension corresponding to the less frequently reinforced element was irrelevant. Conversely, an ED shift would occur when the dimension corresponding to the more frequently reinforced element becomes irrelevant and the less frequently reinforced element became relevant. Faster acquisition following an ID shift than an ED shift would suggest that differential reinforcement in the present procedure produced a change in attentional processing of the elements of the compound samples.

Regardless of where differential reinforcement is ultimately found to have its effects in this procedure, the generalized matching law may provide a useful analysis of stimulus and consequential effects on divided attention performance. Norman (1968) suggested that the allocation of attention depends on the combined effects of sensory activation and pertinence. Sensory activation reflects the sensory properties of a stimulus and is related to properties such as stimulus salience and intensity. Pertinence reflects the importance of the stimulus to the organism, therefore reflecting the organism's history with the stimulus and its current goals. As applied here, the generalized matching law permits quantification of stimulus-based biases (i.e., $\log b$ ) independent of variables impacting the pertinence of two stimuli. For example, the bias in favor of colors over line stimuli in the present experiment likely reflects the impact of stimulus-based factors. On the other hand, the sensitivity parameter (i.e., $a$ ) may be considered to reflect the impact of differences in the pertinence of two stimuli independent of stimulus-based biases. Thus, higher accuracies with higher relative reinforcement rates can be considered to reflect the greater pertinence of the more richly reinforced element, above and beyond biases in performance produced by differences in the physical properties of the stimuli. Thus, in future work it should be possible to simultaneously and independently measure the effects of variations in both stimulus-related properties and motivational variables on divided attention performance, and perhaps to provide an animal analogue of the top-down control of attention induced by instructional sets in the human cognition laboratory. Furthermore, such work might contribute to a more general quantitative account of how differential consequences contribute to decision processes involved in the allocation of attention.

\section{REFERENCES}

Baum, W. M. (1974). On two types of deviation from the matching law: Bias and undermatching. Journal of the Experimental Analysis of Behavior, 22, 231-242.

BAUM, W. M. (1979). Matching, undermatching, and overmatching in studies of choice. Journal of the Experimental Analysis of Behavior, 32, 269-281.

Blough, D. S. (1969). Attention shifts in a maintained discrimination. Science, 166, 125-126.

Davison, M. [C.], \& McCarthy, D. (1988). The matching law: A research review. Hillsdale, NJ: Erlbaum.

Davison, M. [C.], \& Nevin, J. A. (1999). Stimuli, reinforcers, and behavior: An integration. Journal of the Experimental Analysis of Behavior, 71, 439-482. 
Davison, M. C., \& Tustin, R. D. (1978). The relation between the generalized matching law and signal detection theory. Journal of the Experimental Analysis of Behavior, 29, 331-336.

Dias, R., Robbins, T. W., \& Roberts, A. C. (1996). Primate analogue of the Wisconsin card sorting test: Effects of excitotoxic lesions of the prefrontal cortex in the marmoset. Behavioral Neuroscience, 110, 872-886.

Gopher, D. (1992). The skill of attention control: Acquisition and execution of attention strategies. In D. E. Meyer \& S. Kornblum (Eds.), Attention and performance XIV: Synergies in experimental psychology, artificial intelligence, and cognitive neuroscience (pp. 299-322). Cambridge, MA: MIT Press.

Gottselig, J. M., Wasserman, E. A., \& Young, M. E. (2001). Attentional trade-offs in pigeons learning to discriminate newly relevant visual stimulus dimensions. Learning \& Motivation, 32, 240-253.

Herrnstein, R. J. (1961). Relative and absolute strength of response as a function of frequency of reinforcement. Journal of the Experimental Analysis of Behavior, 4, 267-272.

Lacourse, D. M., \& Blough, D. S. (1998). Effects of discriminability, probability of reinforcement, and handling cost on visual search and prey choice. Animal Learning \& Behavior, 26, 290-298.

LAMB, M. R. (1991). Attention in humans and animals: Is there a capacity limitation at the time of encoding? Journal of Experimental Psychology: Animal Behavior Processes, 17, 45-54.

LANGLEY, C. M., \& RILEY, D. A. (1993). Limited capacity information processing and pigeon matching-to-sample: Testing alternative hypotheses. Animal Learning \& Behavior, 21, 226-232.

LEITH, C. R., \& MAKI, W. S. (1975). Attention shifts during matchingto-sample performance in pigeons. Animal Learning \& Behavior, 3, 85-89.

Lovejoy, E. (1965). An attention theory of discrimination learning. Journal of Mathematical Psychology, 2, 342-362.

LuBow, R. E. (1989). Latent inhibition and conditioned attention theory. New York: Cambridge University Press.

LucK, S. J., \& Vecera, S. P. (2002). Attention. In H. Pashler \& S. Yantis (Eds.), Stevens ' Handbook of experimental psychology: Vol. 1. Sensation and perception (3rd ed., pp. 235-286). New York: Wiley.

Mackintosh, N. J. (1974). The psychology of animal learning. New York: Academic Press.

Mackintosh, N. J. (1975). A theory of attention: Variations in the associability of stimuli with reinforcement. Psychological Review, 82 , 276-298.

Mackintosh, N. J., \& LitTLE, L. (1969). Intradimensional and extradimensional shift learning by pigeons. Psychonomic Science, 14, 5-6.

MAKI, W. S., \& LeITH, C. R. (1973). Shared attention in pigeons. Journal of the Experimental Analysis of Behavior, 19, 345-349.

MAKI, W. S., \& LEUIN, T. C. (1972). Information-processing by pigeons. Science, 176, 535-536.

McIlvane, W. J., Dube, W. V., \& Callahan, T. D. (1996). Attention: A behavior analytical perspective. In G. R. Lyon \& N. A. Krasnegor (Eds.), Attention, memory, and executive function (pp. 97-117). Baltimore: Brookes.

Nevin, J. A., Davison, M., \& Shahan, T. A. (2005). A theory of attending and reinforcement in conditional discriminations. Journal of the Experimental Analysis of Behavior, 84, 281-303.
Norman, D. A. (1968). Toward a theory of memory and attention. Psychological Review, 75, 522-536.

Norman, D. A., \& Shallice, T. (1986). Attention to action: Willed and automatic control of behavior. In R. J. Davidson, G. E. Schwartz, \& D. Shapiro (Eds.), Consciousness and self-regulation (Vol. 4, pp. 1-18). New York: Plenum.

PASHler, H. E. (1998). The psychology of attention. Cambridge, MA: MIT Press.

Posner, M. I. (1980). Orienting of attention. Quarterly Journal of Experimental Psychology, 32, 3-25.

Riley, D. A., \& Leith, C. R. (1976). Multidimensional psychophysics and selective attention in animals. Psychological Bulletin, 83, 138160

Riley, D. A., \& Roitblat, H. L. (1978). Selective attention and related cognitive processes in pigeons. In S. H. Hulse, H. Fowler, \& W. K. Honig (Eds.), Cognitive processes in animal behavior (pp. 249-276). Hillsdale, NJ: Erlbaum.

Roberts, W. A. (1998). Principles of animal cognition. Boston: McGrawHill.

Santi, A., Grossi, V., \& Gibson, M. (1982). Differences in matchingto-sample performance with element and compound sample stimuli in pigeons. Learning \& Motivation, 13, 240-256.

Schroeder, S. S., \& Holland, J. G. (1969). Reinforcement of eye movement with concurrent schedules. Journal of the Experimental Analysis of Behavior, 12, 897-903.

Shull, R. L., \& Pliskoff, S. S. (1967). Changeover delay and concurrent schedules: Some effects on relative performance measures. Journal of the Experimental Analysis of Behavior, 10, 517-527.

Styles, E. A. (1997). The psychology of attention. Hove, U.K.: Psychology Press.

Sutherland, N. S., \& Mackintosh, N. J. (1971). Mechanisms of animal discrimination learning. New York: Academic Press.

Temple, W., Scown, J. M., \& Foster, T. M. (1995). Changeover delay and concurrent-schedule performance in domestic hens. Journal of the Experimental Analysis of Behavior, 63, 71-95.

Wasserman, E. A., \& Miller, R. R. (1997). What's elementary about associative learning? Annual Review of Psychology, 48, 573-607.

YANTIS, S. (2000). Goal-directed and stimulus-driven determinants of attentional control. In S. Monsell \& J. Driver (Eds.), Control of cognitive processes: Attention and performance XVIII (pp. 73-103). Cambridge, MA: MIT Press.

Zeaman, D., \& House, B. J. (1963). The role of attention in retardate discrimination learning. In N. R. Ellis (Ed.), Handbook of mental deficiency: Psychological theory and research (pp. 159-223). New York: McGraw-Hill.

Zentall, T. R. (2005). Selective and divided attention in animals. Behavioural Processes, 69, 1-15.

Zentall, T. R., \& Riley, D. A. (2000). Selective attention in animal discrimination learning. Journal of General Psychology, 127, 45-66.

Zentall, T. R., Sherburne, L. M., \& Zhang, Z. (1997). Shared attention in pigeons: Retrieval failure does not account for the element superiority effect. Learning \& Motivation, 28, 248-267.

(Manuscript received December 5, 2005; revision accepted for publication February 3, 2006.) 